\title{
A Panel Data Approach to the Measurement of Health Technical Efficiency of Sub-Saharan Africa
}

\author{
Elham Torkian*
}

\begin{abstract}
This study investigates technical efficiency of health production function in Sub-Saharan Africa. For this purpose, a stochastic production frontier model is estimated using fixed-effects panel data method over the period of 2000-2007. More specifically the impact of economic, social, and environmental factors in determining life expectancy at birth, as the dependent variable, is measured and evaluated. Overall, the results justify the important role of policymakers, who their proactive approaches should be given to activities that go beyond the health system to influence the main determinants of health i.e. socioeconomic and environmental factors in preventing infectious diseases, improving life expectancy and aid populations to access available resources.
\end{abstract}

Keywords: Sub-Saharan Africa, Health production function, Technical efficiency, Panel data

JEL Classification: C12; C23; I12; I15

\section{Introduction}

There are growing evidences that health is a principal part of sustainable development efforts. Health is considered as a capability which makes the life of human being more valuable. Considering this fact that health is one of the essential and inevitable needs of a society, development specialist and policy makers have focused their attention on seeking a viable and efficient mechanism for improving the health status of society.

Some African development specialist and policy makers with various continental and international initiatives have also focused on healthcare delivery issues and have undertaken important steps in this regard. There has been a marked increase

\footnotetext{
* Elham Torkian is at Islamic Azad University, Department of Economics, Khorasgan (Isfahan) Branch, Iran.
} 
in intervention and support for health in the Sub-Saharan Africa (SSA) over the past years. In fact, the region has witnessed considerable change concerning the provision of resources for health services, even in the poorest countries. Although this was a remarkable development, these resources have induced huge emphasis on a small health labour force and limited organisational capabilities. This was due to the paucity of capacities for planning and managing these resources and fundamental limitations in essential infrastructures. This situation is compounded by the prevalence of infectious diseases, poverty, conflict and poor governance. The combined impact of these conditions causes the residents of SSA to have the world's shortest life expectancy. Furthermore high mortality rates among the most productive segments of the population, sabotage their struggling economies.

Therefore, efficiency determination is very essential for policy makers and statesmen who are concerned about improving the efficiency of health system. Because it helps recognising the conditions for improving and justifying economic circumstances, reducing the waste of resources, and using them in an efficient way to deliver health services and speeding up the economic growth. In the meantime, determining the effective factors such as economic, social, and environmental factors on increasing life expectancy as the community's health output, followed by estimating technical efficiency of this production process, could also be very useful.

An extensive body of literature has addressed the empirical measurement of efficiency in health care system ${ }^{1}$. But most of them have been employed frontier efficiency measurement techniques in assaying the efficiency of many different types of institutions. These include hospitals, physician practices, nursing homes, health maintenance organisations, and substance abuse treatment organisations. In these studies, a few articles have considered the efficiency of health care in terms of health production function. These kinds of articles either in terms of one output or multiple output models, in both DEA and SFA methods, expressed the cross-country comparison of technical efficiency of health production function.

On the other hand, health economists have been interested in the impact of marginal contribution of selected environmental, socioeconomic, behavioural, and medical inputs on various measures of health outcomes. To investigate these relationships, empirical studies have adopted a health production function analytical framework, where health is viewed as an output that is produced by a set of inputs. For this purpose, some studies like Auster, Levenson and Sarachek (1969), Silver (1972), Hadley (1982), Thornton (2002), and Fayissa and Gutema (2005) have attempted to estimate an aggregate, multifactor health production function. ${ }^{2}$

Based upon this, the present study attempts to measure the technical efficiency of health production function by applying the panel data model, based on production function introduced by Fayissa and Gutema (2005). The general advantage of measuring the technical efficiency by an aggregate production function, is in such a way 
that it can help policymakers and statesmen in designating and orientating macro policies along with the economic growth and increasing society's welfare, beside optimising the correct use of resources.

The remainder of the paper is organised as follows. Section 2 includes an empirical framework derived from the proposed theoretical model by Fayissa and Gutema (2005) and the stochastic frontier analysis method by using panel data model. Data presentation covers Section 3. Section 4 describes econometric approach followed in the estimation process. In section 5 we report the empirical estimation results. And finally, the conclusion comes in section 6 .

\section{Empirical Framework}

Fayissa and Gutema (2005) presented an empirical health production function in a linear logarithmic form of the Cobb-Douglas production function through generalisation of health production function developed by Grossman (1972) based on micro-economic data for macro-economic data, which can be specified as:

$$
h_{i t}=\Omega+y_{i t}^{\prime} \alpha+s_{i t}^{\prime} \beta+v_{i t}^{\prime} \zeta+v_{i t}
$$

where

$$
\Omega_{i t}=\Omega-u_{i t}
$$

The subscripts $i$ and $t$ represent country and time, respectively; $h$ is natural logarithm of average health status of country $i ; \Omega_{i t}$ are estimations of the initial health stock of the region; $y$ is natural logarithm vector of economic factors; $s$ is natural logarithm vector of social factors; $v$ is natural logarithm vector of environmental factors; $\alpha, \beta$ and $\zeta$ are vectors of unknown economic, social and environmental factors parameters to be estimated, respectively; the $v_{i t}$ are random variables which are assumed to be independent, uncorrelated with the regressors and often assumed to be normally distributed. Technical inefficiency is represented by $u_{i t}$. The $u_{i t}$, other than it being non-negative, are determined by the specific model.

The problem with this specification is that with a $N \times T$ panel, it is impossible to estimate all of the N.T intercepts, the $K$ slopes and $\sigma_{v}^{2}$. To avoid this problem, Cornwell, Schmidt and Sickles (1990) replacenwith a flexible parameterised function of time with parameters that vary over time. The quadratic form of this is:

$$
\Omega_{i t}=\theta_{i 1}+\theta_{i 2} t+\theta_{i 3} t^{2}
$$


As a result, only N.3 intercepts need to be estimated with this setup. Additionally, the ratio of parameters to be estimated to the number of observations is $\frac{(3 N+K+1)}{N} T$.

This topic will include estimation by random effects $(\mathrm{RE})$ and fixed effects $(\mathrm{FE})^{3}$. In the RE model, the $u_{i t}$, are assumed to be randomly distributed with a constant mean and variance. The GLS estimator is used and consistency hinges on the uncorrelatedness of $u, v$ and the regressors.

The FE model has two methods for obtaining technical efficiency depending on the size of N/T. If the ratio is relatively large, then the's are deleted from the Eq. (2). The slopes are estimated from the residuals, and the residuals are regressed on a constant, $t$ and $t^{2}$ to obtain the estimates of $\theta_{i 1}, \theta_{i 2}$ and $\theta_{i 3}$, which this procedure will produce a value for $\Omega_{i t}$.

Alternatively, if $N / T$ is relatively small, then the $u_{i t}$ 's are included in the model. In this case, the parameters of Eq. (3) are estimated as the coefficients of dummies. This will give a similar estimated form of the intercepts. The estimated intercepts determine $\hat{u}_{i t}$, which is equal to:

$$
\hat{u}_{i t}=\max _{\text {it }}-\hat{\Omega}_{i t}
$$

Finally, technical efficiency for a specific firm in period $t$, in the logarithmic case, is defined to be:

$$
T E_{i t}=\exp \left(-\hat{u}_{i t}\right)
$$

\section{Statistical Data}

The required data for this study was taken from World Bank 2010 in the format of World development Index. Due to missing some observations, the study has confined to the period of 2000-2007 and to 33 Sub-Sahara African countries.

The selection of variables in an empirical analysis should be based on availability and reliability of the data. According to Behrman and Deolalikar (1988) life expectancy, particularly at birth and mortality rate, particularly for infants and children would suggest as indicators of health output for aggregate studies. In this empirical analysis, we utilise life expectancy at birth as the dependent variable. It indicates the number of years a newborn infant would live if prevailing patterns of mortality at the time of its birth were to stay the same throughout its life. Also, Behrman and Deolalikar (1988) exhort that care must be taken in empirical analysis to consider 
an appropriate range of the inputs and not just those that are identified with public health measure or curative medicine in developed countries. Consequently, in this empirical study, the variables representing economic factors $(y)$ are limited to GDP per capita $\left(y_{1}\right)$ which is calculated in constant US dollars and is expected to have a positive coefficient i.e. a higher level of income permits more access to consumption of higher quality of goods and services, medical care services, and better housing which favourably influence the health status. Moreover, as income increases, there is a general tendency to move away from jobs with higher stress which may adversely affect health status ${ }^{4}$; the ratio of total health expenditure to GDP $\left(y_{2}\right)$ as indicator of availability of the facilities per capita. For reducing the possible effects of multicollinierty that arises from co-movement of health expenditures and income, it is used as the ratio of total health expenditure to GDP. It covers the provision of health services, family planning activities, and emergency aid designed for health. The expected relationship between health expenditure and life expectancy is somewhat ambiguous. Fayissa and Gutema (2005) state that higher levels of per capita health expenditures may help to increase the provision of health facilities, which in may turn help, improve life expectancy. But, this is only true if the increment in expenditure has no adverse effect on the individual's health status. An adverse effect may arise if the expenditures are financed by revenues collected from user fees, or taxes, and if the fees and tax payments are made at the expense of the individual preventive health care such as food, clothing, and housing as which may occur in subsistence societies. In this situation, unless the marginal effect of an increase in the facility is so high to compensate the forgone benefits from preventive health care, it is normal to obtain a negative coefficient ${ }^{5}$ for the variable. Therefore, the sign of the coefficient cannot be predicted a priori; and food production index ${ }^{6}\left(y_{3}\right)$ as a measure of food availability. It covers food crops that are considered edible and that contain nutrients. This index requires inserting population in the function as a correction of aggregation figures to per capita levels. The food production index exists in aggregate form rather than appearing in per capita form, but what is needed is per capita availability of food. The population variable is introduced in the function to correct the food availability index. It covers food crops that are considered edible and that contain nutrients. Coffee and tea are excluded because they have no nutritive value. Given that the problem of nutrition in poor economies is more of scarcity and not of over consumption, we expect positive coefficient for food availability. Variables representing the social factors $(s)$ are limited to literacy rate $\left(s_{1}\right)$ which is taken as a proxy for education. It is the percentage of people above 15 years who cannot read, write and understand a simple statement on their daily activities. Grossman (1972) and other studies have argued that education influences many decisions such as a choice of job, ability to select a healthy diet, avoid unhealthy habits, and efficient use of medical care which impacts the quality of life. Berger and Leigh (1989) and Rosen and Taubman (1982) have provided empirical evidence in support of this argument. We, therefore, hypoth- 
esise that the more literate society has healthier people, and hence we expect a positive coefficient of adult literacy rate; population $\left(s_{2}\right)$ which is a demographic social factor, here it appears in the function in relation with food availability as mentioned before. Keeping all else constant, we believe that improvement of life conditions has led to population increase in the long term by reducing mortality rate, and therefore, population multiplication is tied to a healthier society, thus the impact of population on health production could be positive; and prevalence of HIV (\% of population ages 15-49) $\left(s_{3}\right)^{7}$ which refers to the percentage of people ages $15-49$ who are infected with HIV. AIDS is one of the greatest public health and social problems threatening the human race. It is a disease that weakens the immune system, making sufferers vulnerable to dangerous, potentially life-threatening infections. As the epidemic worsens the incidence of HIV transmission increases. AIDS has played a significant role in the reversal of health status in SSA. Therefore, we expect a negative coefficient of HIV prevalence. And ultimately, urbanisation rate or the share of total population living in areas defined as urban in each country $\left(v_{1}\right)$; and carbon dioxide emissions per capita $\left(v_{2}\right)$ which are emissions stemming from the burning of fossil fuels and the manufacture of cement. They include carbon dioxide produced during consumption of solid, liquid, and gas fuels and gas flaring representing the environmental factors (v). Thornton (2002) indicates that urbanisation is associated with pollution and congestion that has an adverse effect on health. Moreover, it is argued that in urban areas clinics are more cost-effective and would bring health care knowledge to families. Therefore, the sign of urbanisation cannot be predetermined. The carbon dioxide emissions cause air pollution that in turn causes health hazards, so we expect negative coefficient for the variable.

\section{Panel Method}

As mentioned before, we use panel data for estimating technical efficiency of health production. Panel data estimation is often considered to be an efficient analytical method in handling econometric data. The combined panel data matrix set consists of a time series for each cross sectional member in the data set, and offers a variety of estimation methods. In this case the number of observations available increase by including developments over time.

The question of whether to pool the data or not naturally arises with panel data. The restricted model is the pooled model representing a behavioural equation with the same parameters over time and across regions. The unrestricted model, however, is the same behavioural equation but with different parameters across time or across regions Baltagi (2005).

Generally, most economic applications tend to be of the first type, i.e. with a large number of observations on individuals, firms, economic sectors, regions, industries 
and countries but only over a few time periods. Thus, we use the tests for the poolability of the data for the case of pooling across regions keeping in mind that the other case of pooling over time can be obtained in a similar fashion.

\section{Test for Poolability}

For testing the poolability of data we should use Chow test presented by Chow (1960). For our data Chow's test for poolability across countries gives an observed F-statistic of 181.77 and is distributed as $\mathrm{F}(32,223)$ under $H_{0}: \delta_{i}=\delta$ for $i=1,2, \ldots, N$. The test reject poolability across countries for all coefficients.

\section{Panel Unit Root Test}

Both DF and ADF unit root tests are extended to panel data estimations, to consider cases that possibly exhibit the presence of unit roots. Most of the panel unit root tests are based on an extension of the ADF test by incorporating it as a component in regression equations. However, when dealing with panel data, the estimation procedure is more complex than that used in time series.

There are a variety of panel unit root tests which include Breitung (2000), Hadri (2000), Choi (2001), Levin, Lin and Chu (2002), and Im, Pesaran and Shin (2003) among others. Consider the following autoregressive specifications:

$$
Y_{i t}=\rho_{i} y_{i t-1}+\delta_{i} X_{i t}+\varepsilon_{i t}
$$

where $i=1, \ldots, N$ for each country in the panel; $t=1, \ldots, T$ refers to the time period; $X_{i t}$ represent the exogenous variables in the model including fixed effects or individual time trend; $\rho_{i}$ are the autoregressive coefficients; and $\varepsilon_{i t}$ are the stationary error terms. If $\rho_{i}<1, Y_{i t}$ is considered weakly trend stationary whereas if $\rho_{i}=1$, then $Y_{i t}$ contains a unit root.

Where $p_{i}$ represent the number of lags in the ADF regression. The null hypothesis is that each series in the panel contains a unit root; $\left(H_{0}: \rho_{i}=1\right)$ the alternative hypothesis is that at least one of the individual series in the panel is stationary $\left(H_{0}\right.$ $\left.: \rho_{i}<1\right)$.

For our empirical model the result in table 1 shows that the null hypothesis of a unit root is not accepted for the level of each variable. Thus, our empirical results for the unit root tests are not to be robust to the choice of sample period. 
Table 1: Panel unit root test

\begin{tabular}{|c|c|c|c|c|c|c|c|c|c|}
\hline Variables & $\operatorname{Ln}(\mathrm{h})$ & $\operatorname{Ln}\left(y_{1}\right)$ & $\operatorname{Ln}\left(y_{2}\right)$ & $\operatorname{Ln}\left(y_{3}\right)$ & $\operatorname{Ln}\left(s_{1}\right)$ & $\operatorname{Ln}\left(s_{\mathrm{s}}\right)$ & $\operatorname{Ln}\left(s_{3}\right)$ & $\operatorname{Ln}\left(v_{1}\right)$ & $\operatorname{Ln}\left(v_{2}\right)$ \\
\hline $\begin{array}{c}\text { Levin, Lin\& } \\
\text { Chu t-stat }\end{array}$ & -43.7829 & -30.8033 & -29.7850 & -40.9665 & -120000 & -16.1402 & -21.5146 & -4.2327 & -42.7488 \\
\hline P-value & 0.0000 & 0.0000 & 0.0000 & 0.0000 & 0.0000 & 0.0000 & 0.0000 & 0.0000 & 0.0000 \\
\hline
\end{tabular}

The motivation toward testing for cointegration is preliminary linked with the provision of investigating the problem of spurious regressions, which exists only in the presence of nonstationarity. In this case, there is no need to test it.

\section{Model Estimation}

In general, simple linear panel data models can be estimated using three different methods: with a common constant in equation, allowing fixed effects, and random effects.

In the fixed effects method the constant is treated as group (section)-specific. This means that the model allows different constants for each group (section). The fixed effects estimator is also known as the least-squares dummy variables (LSDV) estimator because in order to allow for different constants for each group, it includes a dummy variable for each group. To understand this better consider the following model:

$$
Y_{i t}=\alpha_{i}+\beta_{1} X_{1 i t}+\beta_{2} X_{2 i t}+\ldots+\beta_{k} X_{k i t}+u_{i t}
$$

The fixed effects model has following features. FE essentially captures all effects which are specific to a particular individual and do not vary over time. So if we had a panel of countries the fixed effects would take full account of things such as geographical factors, natural endowments and any other of the many basic factors which vary between countries but not over time. Of course this means that we cannot add extra variables which also do not vary over time, such as country size for example, as this variable will be perfectly co-linear with the fixed effect. In some cases FE may involve a very large number of dummy constants as some panels may have many thousand individual members, for example large survey panels. In this case the fixed effect model would use up $\mathrm{N}$ degrees of freedom. This is not in itself a problem as there will always be many more data points than N. However computationally it may be impossible to actually calculate many thousand different constants. In this case many researchers would transform the model by differencing all the variables or be taking deviations from the mean for each variable, which has the effect of removing the dummy constants and avoids the problem of estimating so many parameters. However differencing the model, in particular may be undesirable as it may distort the parameter values and can certainly remove any long run effects. 
On the other hand, the alternative method of estimating a model is the random effects model. The difference between the fixed effects and the random effects method is that the latter handle the constants for each section not as fixed, but as random parameters. The random effects model therefore takes the following form:

$$
\begin{aligned}
& Y_{i t}=\left(\alpha+v_{i}\right)+\beta_{1} X_{1 i t}+\beta_{2} X_{2 i t}+\ldots+\beta_{k} X_{k i t}+u_{i t} \\
& Y_{i t}=\alpha+\beta_{1} X_{1 i t}+\beta_{2} X_{2 i t}+\ldots .+\beta_{k} X_{k i t}+\left(v_{i}+u_{i t}\right)
\end{aligned}
$$

One obvious disadvantage of the random effects approach is that we need to make specific assumptions about the distribution of the random component. Also, if the unobserved group specific effects are correlated with the explanatory variables, then the estimates will be biased and inconsistent. However, the random effects model has some advantages such as it has fewer parameters to estimate compared to the fixed effects method and it allows for additional explanatory variables that have equal value for all observations within a group (i.e. it allows us to use dummies).

\section{The Hausman Test}

The Hausman test is formulated to assist in making a choice between the fixed effects and random effects approaches. Hausman (1978) adapted a test based on the idea that under the hypothesis of no correlation, both OLS and GLS are consistent but OLS is inefficient, while under the alternative OLS is consistent but GIS is not. For the panel data the appropriate choice between the fixed effects and the random effects methods investigates whether the regressors are correlated with the individual (unobserved in most cases) effect. The advantage of the use of the fixed effects estimator is that it is consistent even when the estimators are correlated with the individual effect. The Hausman test uses the following test statistic:

$$
H=\left(\hat{\beta}^{F E}-\hat{\beta}^{R E}\right)\left[\operatorname{var}\left(\hat{\beta}^{F E}\right)-\operatorname{var}\left(\hat{\beta}^{R E}\right)\right]^{-1}\left(\hat{\beta}^{F E}-\hat{\beta}^{R E}\right) \approx \chi^{2}(k)
$$

If the value of the statistic is large, then the difference between the estimates is significant, so we reject the null hypothesis that the random effects model is consistent and we use the fixed effects estimators. In contrast, a small value of the Hausman statistic implies that the random effects estimator is more appropriate. With our data, the resulting Hausman test statistic is 65.18 which, is significant at the $1 \%$ level and we reject the null hypothesis of no correlation between the individual effects and the $X_{i t}$. Therefore, the FE model turns out to be the best specification. 


\section{Empirical Results}

In Table 2, regression results of the FE of life expectancy are reported. According to the results presented in the table, all the estimated coefficients of the Cobb-Douglas production model have signs which generally conform to our expectation and are statistically significant, except for food production index and $\mathrm{CO}_{2}$ emission which are nonsignificant.

Table 2: Panel results (Fixed Effects (WITHIN) Regressions Results)

\begin{tabular}{|c|c|c|c|c|c|}
\hline Prob. & t-Statistic & Std. Error & Coefficient & Parameter & Variable \\
\hline 0.000 & 39.91 & 0.378508 & 1.510796 & $\sigma$ & Constant \\
\hline 0.000 & 6.05 & 0.006488 & 0.039241 & $\alpha_{1}$ & $\left(y_{1}\right)$ \\
\hline 0.005 & 2.79 & 0.006356 & 0.017747 & $\alpha_{2}$ & $\left(y_{2}\right)$ \\
\hline 0.675 & 0.42 & 0.011683 & 0.004902 & $\alpha_{3}$ & $\left(y_{3}\right)$ \\
\hline 0.000 & 6.27 & 0.008688 & 0.054440 & $\beta_{1}$ & $\left(s_{1}\right)$ \\
\hline 0.000 & 4.26 & 0.007597 & 0.032328 & $\beta_{2}$ & $\left(s_{2}\right)$ \\
\hline 0.000 & -7.93 & 0.007841 & -0.062161 & $\beta_{3}$ & $\left(s_{3}\right)$ \\
\hline 0.023 & 2.28 & 0.002134 & 0.004861 & $\zeta_{1}$ & $\left(v_{1}\right)$ \\
\hline 0.744 & -0.33 & 0.005289 & $0.001728-$ & $\zeta_{2}$ & $\left(v_{2}\right)$ \\
\hline
\end{tabular}

It means that the considered economic variables including GDP per capita and the ratio of total health expenditure to GDP are estimated to be positive and acceptably have an influence on the life expectancy. This indicates that a $1 \%$ increment on GDP per capita and the ratio of total health expenditure to GDP will generate about 0.04 and 0.02 percent enhancement in life expectancy, respectively. ${ }^{8}$ Moreover, table 2 reports that the coefficients of literacy rate and population have direct impact, and the prevalence of HIV has an indirect impact on health production, suggesting that a $1 \%$ increment in the two first variable would lead to about 0.05 and 0.03 percent increment in life expectancy, while, a $1 \%$ increment in prevalence of HIV will generate about 0.06 percent reduction in life expectancy. Finally, a $1 \%$ increment in urbanisation rate as the environmental variable produced a positive impact on health production function causes about 0.005 percent increase in life expectancy at birth. Accordingly, health production function for all factor inputs involved is inelastic and elasticity of scale for the Cobb-Douglas production model which was estimated by the sum of the elasticity of the factors indicates that the health production function of the region experiences decreasing return to scale.

For obtaining a similar estimated form of the intercepts, the residuals are regressed on a constant, $t$ and $t^{2}$. These estimated intercepts determine $u_{i t}$. Then technical efficiency for each country in period $t$ which is obtained using Eq. 5 could be presented in Table 3. 
Table 3: Predicted technical efficiency of health production function of each country for the period of 2000-2007

\begin{tabular}{|c|c|c|c|c|c|c|c|c|}
\hline Country & 2000 & 2001 & 2002 & 2003 & 2004 & 2005 & 2006 & 2007 \\
\hline Burundi & 99358 & .99369 & & 99.99392 & 99.99403 & 99.99415 & 9.99426 & 99.99436 \\
\hline Benin & 99447 & 9.99458 & .99469 & 9.99479 & 99.99489 & 99.995 & 99.9951 & 99.9952 \\
\hline Burkina Faso & 3 & 99. & 99.9 & 99.9 & 99.9 & 99.9 & 99.9 & 99. \\
\hline Botswana & .99606 & 99.99615 & 99.99624 & 99.99633 & 99.99641 & 99.9965 & 99.99658 & 99.99667 \\
\hline $\begin{array}{c}\text { Central African } \\
\text { Republic } \\
\end{array}$ & 99.99675 & 99.99683 & 99.99691 & 99.99699 & 99.99707 & 99.99715 & 99.99723 & 99.9973 \\
\hline voire & .99738 & 99.99745 & 99.99752 & 99.99759 & 99.99766 & 99.99773 & 99.9978 & 99.99787 \\
\hline Cameroon & 9.99793 & 99.998 & 99.99806 & 99.99813 & 99.99819 & 99.99825 & 99.99831 & 99.99837 \\
\hline Comoros & .99843 & 99.99848 & 99.99854 & 99.99859 & 99.99865 & 99.9987 & 99.99875 & 99.9988 \\
\hline hiopia & 385 & 89 & 395 & 99.9 & 904 & 908 & 99.99913 & 917 \\
\hline Gabon & 9.99921 & 99.99925 & 99.99929 & 99.99933 & 99.99937 & 99.9994 & 99.99944 & 99.99947 \\
\hline Ghana & .9995 & 99.99953 & 957 & 99.99959 & 99.99962 & 99.99965 & 99.99968 & 99.9997 \\
\hline Gambia, The & 9.99973 & 99.99975 & 99.99977 & 99.99979 & 99.99981 & 99.99983 & 99.99985 & 99.99987 \\
\hline a-Bissau & 9.99989 & 99.9999 & 99.99991 & 99.99993 & 99.99994 & 99.99995 & 99.99996 & 99.99997 \\
\hline Equatorial Guinea & 9.99998 & 99.99998 & 99.99999 & 99.99999 & 100 & 100 & 100 & 100 \\
\hline Liberia & 100 & 100 & 100 & 99.99999 & 99.99999 & 99.99998 & 99.99998 & 99.99997 \\
\hline Mali & .99996 & 99.99995 & 99.99994 & 99.99993 & 99.99991 & 99.9999 & 99.99988 & 99.99987 \\
\hline Mozambique & 9.99985 & 99.99983 & 81 & 99.99979 & 977 & 975 & 99.99972 & 997 \\
\hline Mauritania & .99967 & 99.99965 & 99.99962 & 99.99959 & 99.99956 & 99.99953 & 99.9995 & 99.99947 \\
\hline Mauritius & .99943 & 99.9994 & 99.99936 & 99.99932 & 99.99928 & 99.99925 & 99.99921 & 99.99916 \\
\hline Malawi & .99912 & 9.99908 & 903 & 9899 & 894 & 889 & 885 & 988 \\
\hline Namibia & 9.99875 & 99.99869 & 99.99864 & 99.99859 & 99.99853 & 99.99848 & 99.99842 & 99.99836 \\
\hline Nigeria & .9983 & 99.99824 & 99.99818 & 99.99812 & 99.99806 & 9.99799 & 99.99793 & 99.99786 \\
\hline Rwanda & .99779 & 99.99772 & 99.99765 & 99.99758 & 751 & 99.99744 & 99.99737 & 729 \\
\hline Sudan & 9.99722 & 99.99714 & 99.99706 & 99.99698 & 99.9969 & 99.99682 & 99.99674 & 99.99666 \\
\hline Senegal & .99657 & 99.99649 & 39.9904 & 99.99631 & 99.99623 & 9.99614 & 99.99605 & 99.99595 \\
\hline Swaziland & 586 & 9.99577 & 99.9 & 99.99 & 99.99 & 99.99538 & 99.99529 & 99.99519 \\
\hline Chad & 99.99508 & 99.99498 & 99.99488 & 99.99478 & 99.99467 & 99.99456 & 99.99446 & 99.99435 \\
\hline Togo & 99.99424 & 99.99413 & 99.99402 & 99.99391 & 99.99379 & 99.99368 & 99.99356 & 99.99345 \\
\hline Tanzania & 9.99333 & 99.99321 & 99.99309 & 99.99297 & 99.99285 & 99.99273 & 99.9926 & 99.99248 \\
\hline Uganda & 99.99235 & 99.99223 & 99.9921 & 99.99197 & 99.99184 & 99.99171 & 99.99158 & 99.99144 \\
\hline South Africa & 99.99131 & 99.99117 & 99.99104 & 99.9909 & 99.99076 & 99.99062 & 99.99048 & 99.99034 \\
\hline Zambia & 99.9902 & 99.99005 & 99.98991 & 99.98976 & 99.98962 & 99.98947 & 99.98932 & 99.98917 \\
\hline Zimbabwe & 99.98902 & 99.98887 & 99.98871 & 99.98856 & 99.9884 & 99.98825 & 99.98809 & 99.98793 \\
\hline
\end{tabular}

Note: Because of the same process of the countries in the realm of health production, the estimated efficiency for these countries is approximately close to each other. Moreover, it should be noted that the estimated efficiency is comparative. 
Also, the mean of the technical efficiency of the estimated health function for each country (over the eight-year period), are reported in table 4. It indicates that Equatorial Guinea and Liberia with 99.99999 percent and Zimbabwe with 99.98848 percent have the maximum and the minimum values of technical efficiency of health production function, respectively.

Table 4: Predicted mean technical efficiencies of health production function of each country for the years 2000-2007

\begin{tabular}{|ll|ll|}
\hline Burundi & 99.99398 & Mauritania & 99.99957 \\
\hline Benin & 99.99484 & Mauritius & 99.99929 \\
\hline Burkina Faso & 99.99564 & Malawi & 99.99896 \\
\hline Botswana & 99.99637 & Namibia & 99.99856 \\
\hline Central African Republic & 99.99703 & Nigeria & 99.99809 \\
\hline Cote d'Ivoire & 99.99763 & Rwanda & 99.99754 \\
\hline Cameroon & 99.99816 & Sudan & 99.99694 \\
\hline Comoros & 99.99862 & Senegal & 99.99627 \\
\hline Ethiopia & 99.99901 & Swaziland & 99.99553 \\
\hline Gabon & 99.99935 & Chad & 99.99472 \\
\hline Ghana & 99.99961 & Togo & 99.99385 \\
\hline Gambia, The & 99.99981 & Tanzania & 99.99291 \\
\hline Guinea-Bissau & 99.99993 & Uganda & 99.99185 \\
\hline Equatorial Guinea & 99.99999 & South Africa & 99.99083 \\
\hline Liberia & 99.99999 & Zambia & 99.98969 \\
\hline Mali & 99.99992 & Zimbabwe & 99.98848 \\
\hline Mozambique & 99.99978 & Total average & 99.99675 \\
\hline
\end{tabular}

On the other hand, the annual mean technical efficiency for all the countries reviewed in table 5 implies that technical efficiency tends to decline during the period of investigation.

Table 5: Predicted mean annual technical efficiency for mentioned countries

\begin{tabular}{|c|c|c|c|c|c|c|c|}
\hline 2000 & 2001 & 2002 & 2003 & 2004 & 2005 & 2006 & 2007 \\
\hline 99.99682 & 99.9968 & 99.99678 & 99.99676 & 99.99674 & 99.99672 & 99.9967 & 99.99667 \\
\hline
\end{tabular}

\section{Conclusion}

The study has estimated a stochastic production frontier in order to assess the level of technical efficiency for health production function in Sub-Saharan Africa. The health production data and other relevant information are analysed by estimating a Cobb-Douglas stochastic production frontier by using panel data method. 
The panel data regression results provide some useful information on the healthcare assessment. For life expectancy, GDP, the ratio of total health expenditure to GDP, literacy rate, prevalence of HIV, urbanisation rate and population have played an important role.

Although the estimated results explain appropriate correspondence of model with present data, estimated coefficients show that life expectancy at birth, as a product of health section, is inelastic in relation with all variables considered as its production factors and therefore, none of these factors can have a considerable impact on it. Also, estimated elasticity of scale shows that health section in the studied countries has reached beyond increasing return to scale borders and is in economic production stage.

Furthermore, empirical results show that technical efficiency of health production function tends to decline over the period of investigation. These results justify the important role of policymakers, who their proactive approaches should be given to activities that go beyond the health system to influence the main determinants of health i.e. socioeconomic and environmental factors in preventing infectious diseases, improving life expectancy and aid populations to access available resources.

\section{NOTES}

${ }^{1}$ Brief descriptions of them can be found in Worthington (2004).

${ }^{2}$ It is important to note that a relatively large number of studies have examined the impact of medical care and other factors on health outcomes using the individual as the unit of analysis (see, for example, Newhouse and Friedlander, 1980; Rosen and Taubman, 1982; Taubman and Rosen, 1982; Leigh, 1983; Berger and Leigh, 1989; Kenkel, 1991).

${ }^{3}$ A test may determine which model is appropriate for a particular panel data set. The Hausman-Taylor test allows one to test the uncorrelated hypothesis. This test by Hausman and Taylor (1981), based on Hausman (1978), tests the significance between the within estimator and the GLS estimator.

${ }^{4}$ Some researchers argue that beyond some threshold level of affluence, increasing income may no longer buy better health. In fact, it may lead to a stressful and unhealthy life style that may adversely affect health status (see, for example, Fuchs (1994); Auster et al (1969); Rodgers (1979); Wilkinson (1992); Chistiansen (1994)). Based on this the coefficient of income per capita is expected to be negative. Since income per capita is generally low in SSA, this view is very unlikely to hold, and hence, we expect the sign of the coefficient to be positive.

${ }^{5}$ For a mathematical analysis of the possibility of the negative coefficient see Fayissa and Gutema (2005).

${ }^{6}$ This index is related to the 1999-2001=100 base year.

${ }^{7}$ Fayissa and Gutema (2005) employed lifestyle as a social variable that influences life expectancy in SSA, represented by adult alcohol consumption per capita. But, because of limitation on data availability, we are unable to include any proxy for lifestyle in our study.

${ }^{8}$ As the model is logarithmic linear, the estimated coefficients represent the amount of elasticity of the dependent variable in relation with any of the explanatory variables. 


\section{REFERENCES}

Auster, R., Levenson I. \& Sarachek D. (1969). The production of health: an exploratory study. Journal of Human Resources, 4(4), 411-436. DOI: 10.2307/145166

Baltagi, B.H. (2005). Econometric Analysis of Panel Data. UK: John Wiley and Sons Press.

Behrman, J.R. \& Deolalikar B. (1988). Health and nutrition. In H.B. Chenery \& T.N. Srinivasan (Eds.), Handbook of development economics (pp.631-711). Amsterdam: North-Holland.

Berger, M. \& Leigh J. (1989). Schooling, self-selection, and health. Journal of Human Resources, 24(3), 433-455. DOI: $10.2307 / 145822$

Breitung, J. (2000). The local power of some unit root tests for panel data. Advances in Econometrics, 15(2), 161-177. DOI: http://dx.doi.org/10.1016/S0731-9053(00)15006-6

Chistiansen, T. (1994). Distribution of health status by income. Result from Denmark. In A. Mielck \& M.D.R. Giraldes (Eds.), Health inequalities: discussion in western european countries. NewYork: Waxmann.

Chow, G.C. (1960). Tests of equality between sets of coefficients in two linear regressions. Econometrica, 28(3), 591-605. DOI: 10.2307/1910133

Choi, I. (2001). Unit root tests for panel data. Journal of International Money and Finance, 20(2), 249272. DOI: http://dx.doi.org/10.1016/S0261-5606(00)00048-6

Cornwell, C., Schmidt P. \& Sickles R.C. (1990). Production frontiers with cross-sectional and time-series variation in efficiency levels. Journal of Econometrics, 46(1-2), 185-200.

Fayissa, B. \& Gutema P. (2005). Estimating a health production function for Sub-Saharan Africa (SSA). Applied Economics, 37(2), 155-164. DOI: 10.1080/00036840412331313521

Fuchs, V. (1994). The Future of Health Policy. Cambridge: Harvard University Press.

Grossman, M. (1972). The Demand for Health: A Theoretical and Empirical Investigation. New York: Columbia University Press.

Hadley, J. (1982). More Medical Care, Better Health? An Economic Analysis of Mortality Rates. Washington DC: Urban Institute Press.

Hadri, K. (2000). Testing for stationary in heterogeneous panel data. Econometrics Journal, 3(2), 148161. DOI: $10.1111 / 1368-423 X .00043$

Hausman, J.A. \& Taylor W.E. (1981). Panel data and unobservable individual effects. Econometrica, 49(6), 1377-1398.

Hausman, J.A. (1978). Specification tests in econometrics. Econometrica, 46(6), 1251 -1271. DOI: $10.2307 / 1913827$

Im, K.S., Pesaran M.H. \& Shin Y. (2003). Testing for unit roots in heterogeneous panels. Journal of Econometrics, 115(1), 53-74. DOI: http://dx.doi.org/10.1016/S0304-4076(03)00092-7

Kenkel, D. (1991). Health behaviour, health knowledge, and schooling. Journal of Political Economy, 99(2), 287-305. DOI: $10.1057 / 9780230226203.3869$

Leigh, J. (1983). Direct and indirect effects of education on health. Social Science and Medicine, 17(4), 227-234. DOI: http://dx.doi.org/10.1016/0277-9536(83)90120-X

Levin, A., Lin C.F. \& Chu C. (2002). Unit root test in panel data: asymptotic and finite sample properties. Journal of Econometrics, 108(1), 1-25. DOI: http://dx.doi.org/10.1016/S0304-4076 (01)00098-7

Newhouse, J. \& Friedlander L. (1980). The relationship between medical resources and measures of health: some additional evidence. Journal of Human Resources, 15(2), 200-218. DOI: $10.2307 / 145331$ 
Rodgers, G.B. (1979). Income and inequality as determinants of mortality: an international cross section analysis. Population Studies, 33(2), 343-352. DOI: 10.1080/00324728.1979.10410449

Rosen, S. \& Taubman S. (1982). Some socioeconomic determinants of mortality. In J. Van Der Gagg, W.B. Neeman \& T. Tsukahara (Eds.), Economics of health care. New York: Praeger Publishers.

Silver, M. (1972). An econometric analysis of spatial variations in mortality rates by race and sex. In V. Fuchs (Eds.), Essays in the economics of health and medical care (pp. 161-227). New York: National Bureau of Economic Research.

Taubman, P. \& Rosen S. (1982). Healthiness, education, and marital status. In V. Fuchs (Eds.), Economic aspects of health (pp.121-140). Chicago: University of Chicago Press.

Thornton, J. (2002). Estimating a health production function for the US: some new evidence. Applied Economics, 34(1), 59-62. DOI: 10.1080/00036840010025650

Wilkinson, R.G. (1992). Income distribution and life expectancy. British Medical Journal, 304(6820), 165-168. DOI: http://dx.doi.org/10.1136/bmj.304.6820.165

Worthington, A.C. (2004). Frontier efficiency measurement in health care: a review of empirical techniques and selected applications. Medical Care Research and Review, 61(2), 135-170. DOI: http://dx.doi.org/10.1177/1077558704263796 